\title{
Transformações contemporâneas do trabalho e processos de subjetivação: os jovens face à nova economia e à economia solidária
}

\author{
Henrique Caetano Nardi \\ Denise Balem Yates \\ Universidade Federal do Rio Grande do Sul
}

\begin{abstract}
Resumo
O mercado de trabalho contemporâneo aprofundou o fosso social que separa a população inserida no mercado daquela que sobrevive de forma precária. A economia solidária surgiu como contraponto à fratura social daí decorrente. Utilizando a abordagem biográfica, discutimos as trajetórias de trabalho de 30 jovens divididos em dois grupos. O primeiro grupo é composto por 15 jovens empregados no setor da nova economia (informática, telecomunicações e Internet) e 5 jovens empregados no setor bancário pós-reestruturação; o segundo grupo é composto por 5 jovens ligados a um projeto de economia solidária e 5 jovens vinculados a um projeto comunitário. As entrevistas dos jovens inseridos no primeiro grupo revelam a adesão ao discurso gerencial e a constituição de uma ética individualista. Para os jovens do segundo grupo, a economia solidária e o associativismo constituem somente uma alternativa ao desemprego. Frente a essa constatação, perguntamos se estes projetos se constituem efetivamente como um contraponto à lógica de adesão ao discurso de gestão contemporâneo.
\end{abstract}

Palavras-chave: reestruturação produtiva; subjetividade; abordagem biográfica; nova economia; economia solidária

\begin{abstract}
Contemporary work changes and subjectification processes: young workers facing new economy and social economy. Contemporary labor market increased society's social gap between those inserted in the labor market and those surviving in a precarious way. Social economy emerged in opposition to this social fracture. Using the biographical approach, we discuss work's trajectories of 30 young workers divided in two groups. The first group is formed by 15 workers employed in the new economy sector (telecommunications, Internet and software) and 5 workers employed in reengineered banks. The second group is composed by 5 workers involved in social economy projects and 5 workers involved in a communitarian association. The analysis of the first group's workers' interviews point to the creation/foundation of a highly individualistic ethics and behavior. The workers belonging to the second group seem to explain their experience just as an alternative to unemployment. Due to this conclusion, the question that emerges is if these projects are able to constitute a real opposition to the contemporary management discourse.
\end{abstract}

Keywords: productive reengineering; subjectivity; biographical approach; new economy; social economy

A s transformações nas formas de acumulação e nos regimes de regulação no capitalismo se alteraram pro fundamente nos últimos 30 anos. As competências exigidas para a integração no ciclo produtivo também se modificaram, alterando as possibilidades e as formas de ingresso no mercado de trabalho. Até os anos 1970, a possibilidade do pleno emprego - mesmo que ela nunca tenha se configurado de forma plena no Brasil - exerceu um papel essencial de integração no capitalismo industrial e serviu de via privilegiada de acesso aos direitos sociais. Assim, o acesso aos direitos de forma igualitária estava em relação direta com a objetividade anterior (Castel \& Haroche, 2001), ou seja, as condições materiais de existência que moldam as características dos modos de subjetivação em cada contexto histórico. É, portanto, a partir da articulação trabalho/mercado/subjetividade que propomos analisar duas formas de inserção social via trabalho em dois pólos distintos da nova configuração do capitalismo, levando em conta a especificidade da sociedade brasileira.

A partir da aceitação da premissa de que a relação entre subjetividade e trabalho remete à análise da maneira como os sujeitos vivenciam e dão sentido às suas experiências de trabalho (Nardi, Tittoni, \& Bernardes, 2002), fica evidente que a interpretação dessa relação nos coloca frente à especificidade histórica assumida pela relação dos sujeitos com seu trabalho em cada contexto socioeconômico. Assim, a relação entre 
subjetividade e trabalho muda se analisarmos a relação do cidadão e do escravo com o trabalho na Grécia, do senhor feudal e do servo na Idade Média, do operário da indústria fordista e do jovem analista de sistemas nas empresas ligadas à nova economia no século XXI. É neste sentido que Deleuze (1986), por exemplo, afirma que as mutações do capitalismo engendram a produção de uma nova subjetividade, visto que cada mutação social implica em uma reconversão subjetiva com suas ambigüidades, assim como com seu potencial de resistência e transformação.

Trata-se de pensar a subjetividade através dos processos e dos modos de subjetivação. Para Fonseca (1995), os modos de subjetivação referem-se ao modo predominante como os sujeitos relacionam-se com a regra e a forma como se vêem obrigados a cumprir e, ao mesmo tempo, se reconhecer como ligados a essa obrigação. Os processos de subjetivação, por sua vez, podem ser compreendidos a partir da análise da maneira como cada indivíduo se relaciona com o regime de verdades próprio a cada período, ou seja, a forma como o conjunto de regras que define cada sociedade é experienciado em cada trajetória de vida.

O trabalhador da modernidade definia-se a partir de um regime de verdades (Foucault, 1994) que determinava uma forma de ser e existir no qual o trabalho constituía-se como elemento central e determinante do código moral que estabelecia as regras de conduta e guiava o julgamento das ações com relação à estrutura da família, à educação dos filhos, à ação política e determinava a natureza central do laço social. A indústria representava o setor da economia que guiava os Estados à independência e ao desenvolvimento econômico e social.

Como fruto deste modelo, o período posterior à II Guerra Mundial consolidou na Europa um modelo de Estado Nação e de organização societária baseados no assalariamento da maioria da população e sobre o qual se construiu o aparato institucional que constitui o que Castel (1998) denominou como a propriedade social.

A propriedade social constituiu-se no elemento central do Estado Social e representava o suporte social para o exercício da igualdade de direitos. Este Estado "protetor" garantiu o acesso igualitário aos direitos sociais pela via da oferta de serviços públicos e formas de suporte social tais como a habitação de baixo custo (ou a ajuda financeira para a locação), sistema de saúde público, creches, asilos, educação pública universal, seguro desemprego; enfim, um conjunto de suportes que podem ser alocados sob a denominação genérica de seguridade social. A construção desse aparato institucional só foi possível graças à generalização da oferta de trabalho na sua forma emprego. O trabalho representava a garantia moral (do ponto de vista simbólico) e material (do ponto de vista concreto) do exercício da cidadania plena. Este modelo, mesmo que nunca tenha sido implantado completamente no terceiro mundo e no Brasil em particular, serviu de modelo para a construção de uma sociedade centrada no trabalho industrial ${ }^{1}$. O conceito de cidadania regulada definido por Santos (1979) e discutido por Gomes (1982), afirma que a aquisição dos direitos sociais no Brasil esteve associada ao assalariamento e à estratificação profissional. A carteira assinada exercia o papel de um atestado de "moralidade" exemplar.

Outro fator fundamental que estabelece a diferença entre o presente e o passado recente na sociedade brasileira referese às transformações da dimensão temporal no planejamento possível das trajetórias de vida. O trabalho na modernidade permitiu o planejamento a longo prazo na construção dos projetos de vida. O trabalho baseado na experiência e na dedicação era a garantia para o acesso aos bens materiais e para a construção de uma vida estruturada e previsível dentro de um código moral claro, mas, ao mesmo tempo, restritivo. O estudo de Colbari (1995) mostra como a dedicação à família e ao trabalho constituíam-se em características centrais dos processos de subjetivação do homem trabalhador. O fator de identificação principal associava a disciplina do trabalho ao papel de provedor da família. A noção de provedor de família pode ser caracterizada quase como um tipo ideal - no sentido weberiano - se considerarmos a interpretação de Colbari das trajetórias de vida dos ganhadores do concurso Operário Padrão do Brasil.

A crítica do código moral restritivo da modernidade foi, de acordo com Boltanski e Chiapello (1999), incorporada de forma instrumentalizada pelo discurso gerencial que emerge a partir dos anos 1980. O novo discurso define o ideal de trabalhador como flexível, competitivo e individualista. Os padrões daquilo que é considerado correto ou incorreto moralmente passam a obedecer a um critério de custo/benefício, abandonando os princípios guias que permitiram conduzir as escolhas de vida no longo prazo (Sennett, 1998).

As transformações do mundo do trabalho, decorrentes da última crise do capitalismo, transformaram a base material e simbólica associada ao trabalho. O esgotamento do modelo fordista-taylorista; a terceira revolução industrial (a associação da informática e das telecomunicações); a globalização; a criação dos blocos econômicos; o fim da guerra fria; a falência do socialismo real e a crise dos grandes discursos explicativos e totalizantes, entre uma série de outros aspectos, são fatores determinantes do estado de incertezas em que se encontra o mundo e as instituições sociais que serviram de base para a regulação societária e que garantiram uma determinada segurança ontológica (Giddens, 1989) na modernidade.

Essas mudanças no modelo produtivo se associam à crise da sociedade salarial na Europa e à emergência de uma zona de vulnerabilidade social no seio das sociedades industriais (Castel, 1998).

No Brasil, a destruição do Estado Social em sua fase embrionária - idealizada pela constituição de 1988, mas abortada pela onda liberal dos governos Fernando Collor e Fernando Henrique Cardoso - e o incremento da flexibilização das relações de trabalho relacionam-se à precarização, por um lado, e ao aumento das exigências de qualificação, pelo outro. Estes elementos associados constituem uma nova conjuntura global/local e configuram a posição do Brasil na nova divisão internacional do trabalho, além de produzir o incremento das desigualdades estruturais da sociedade brasileira. 
A partir dessa nova configuração das formas de inserção no mercado de trabalho buscamos investigar neste artigo: por um lado, os trabalhadores da ponta mais avançada do mercado de trabalho atual (a nova economia), ou seja, os jovens (de até 30 anos) inseridos em áreas consideradas como de vanguarda em relação às inovações tecnológicas e organizacionais - informática e Internet e a telecomunicação móvel (celular) e os bancos (por representarem um dos setores que mais sofreu alterações com a reestruturação produtiva) - e, pelo outro, os jovens que não se inseriram no mercado de trabalho formal e que estão vinculados a projetos de economia solidária. É importante esclarecer ao leitor que o termo jovem é usado aqui de forma ampliada, não se restringindo às categorias do IBGE (até 24 anos). Uma vez que ao buscarmos construir uma estratégia comparativa de análise e sabendo que o acesso às ocupações da nova economia depende de formação universitária, utilizamos como critério de corte a idade de 30 anos. Além deste critério, e como nos demonstra Petras (1999), as novas exigências do mercado têm ampliado a idade de entrada no mercado de trabalho formal.

\section{A abordagem biográfica como forma de compreensão das transformações contemporâneas}

A articulação téorico-metodológica se construiu a partir da compreensão do jogo de verdades sobre o trabalho e seus efeitos nos processos de subjetivação. Buscamos nas projeções que os trabalhadores fazem de seu ideal e, em oposição, do não-ideal de suas situações de vida e trabalho, os efeitos dos discursos veiculados sob a forma de saber. Para Foucault (1987), quando alguém fala veiculando um discurso, o que está em questão, quanto à autoria, não é somente a subjetividade de quem fala, mas também o lugar que se ocupa ao falar.

$\mathrm{O}$ instrumento de pesquisa que utilizamos consiste em entrevistas aprofundadas que buscaram reconstruir as trajetórias de vida dos trabalhadores. A técnica de pesquisa foi escolhida por ser a mais adaptada para entender como os sujeitos construíram suas vidas a partir da inserção (ou da tentativa de) no mercado de trabalho. Os relatos nos possibilitaram descrever e entender como o trabalho atravessa os processos de subjetivação e como os sujeitos trabalhadores realizam os julgamentos morais que conduzem suas vidas em sociedade e seus engajamentos no laço social.

A utilização do método biográfico nos permite (Cabanes, 2002) abordar o coletivo pelo individual. Por meio das trajetórias de vida e da proposição de um dilema ético ${ }^{2}$ aos entrevistados, foi possível estabelecer quais parâmetros balizam a reflexão ética construída pelos indivíduos a partir de sua compreensão das normas sociais presentes nos contextos nos quais estão inseridos. A análise da construção das individualidades em interação é possível mediante a abordagem das trajetórias de vida. Trata-se do estudo do espaço ocupado pelo sujeito no contexto social, de uma posição que se constrói não como um dado definitivo, não como uma posição fixa na estrutura social, mas como uma tarefa, ou uma obra, constantemente em produção. Cabanes (2002) afirma: "Mais pre- cisamente, somente o relato biográfico - récit biographique - permite efetuar a primeira parte do projeto que é a condição para a análise da construção social da relação consigo mesmo” (p. 417). A utilização da noção de ideal de nós (idéal de nous), proposta pelo autor, e derivada do conceito de ideal de eu, é bastante frutífera na análise das trajetórias de vida, uma vez que remete a um ideal de construção societária/comunitária ou de grupo de pertencimento.

Nossa análise buscou superar a crítica de Bourdieu (1986) às análises centradas nas trajetórias de vida, uma vez que a mesma se referia à descontextualização dos relatos. Concordamos com Bourdieu, quando ele afirma que não se pode compreender uma trajetória sem que se tenha estabelecido as etapas sucessivas do campo no qual esta trajetória teve lugar, ou seja, o conjunto de relações objetivas que marcam o contexto. A sucessão de posições que marcam uma trajetória de vida está relacionada ao espaço social no qual ela se desenvolve. Os acontecimentos que marcam uma biografia se definem pelos deslocamentos no espaço social, "pelos diferentes estados sucessivos da estrutura de distribuição dos diferentes tipos de capital que estão em jogo em cada campo considerado" (Bourdieu, 1986, p. 71).

A análise das entrevistas, por sua vez (Beaud \& Weber, 1998), não deve se restringir a exemplificar categorias e hipóteses preestabelecidas, realizando a simples retranscrição literal, reduzindo o comentário ao mínimo, nem tampouco tomálas como uma simples fonte de informações do mundo exterior, mas sim e imperativamente, entendê-las como fatos de linguagem e, como tal, compreender que as entrevistas são a materialização do social em palavras. O resultado da interpretação deve ter por princípio a busca da estrutura que ordena as categorias de análise, que organiza a produção dos relatos e que, ao mesmo tempo, estabelece a dinâmica da inserção dos relatos no contexto social.

De acordo com Ferraroti (1983), o método de investigação das histórias de vida transforma em real e dá sentido humano ao esquema conceitual e intemporal de produçãotroca-consumo-produção. A biografia individual tem sentido se estabelecemos a relação entre a trajetória de vida e as características da situação histórica vivida e datada. É desta forma que o approach biográfico se autonomiza e podemos construir o estatuto científico do aspecto subjetivo inerente a um relato biográfico, o qual, por sua vez, é construído a partir de uma interação complexa entre o narrador e o observador/entrevistador. Para Ferraroti (1997), uma vida consiste na prática de apropriação das estruturas sociais num jogo permanente de interiorização, transformando-as em estruturas psicológicas por uma atividade de desestruturação/ reestruturação. Cada vida humana é a síntese vertical de uma história social. Não se trata simplesmente de refletir o social, o indivíduo se apropria do social, e, através de um processo de mediação, o filtra, e o retraduz ao projetá-lo em uma outra dimensão, aquela que, consequentemente, vai compor sua subjetividade.

Em suma, podemos afirmar que as relações entre os sujeitos entrevistados e seu trabalho foram analisadas levando 
em conta os aspectos descritos até aqui. Buscamos, assim, identificar os dispositivos que atuam nos processos de subjetivação, para, desta forma, compreender os parâmetros que balizam a reflexão ética dos trabalhadores em relação à vida em sociedade, ou seja, à decodificação das regras morais presentes no jogo de verdades próprio a cada época. Estes dispositivos compreendem sanções sociais que agenciam modos de ser. Dependem, portanto, das relações de poder presentes nos jogos de dominação e resistência que inscrevem os indivíduos na vida em sociedade.

Discutiremos a seguir as trajetórias de vida e trabalho de 30 jovens trabalhadores. Não apresentaremos os relatos integrais das entrevistas, pois não haveria espaço no artigo. Como alternativa à forma clássica de apresentação das trajetórias de vida, buscaremos identificar as características centrais de cada grupo e subgrupo, assim como suas peculiaridades e diferenças internas. A Tabela 1 apresenta a distribuição dos entrevistados considerando a inserção profissional e o setor da Economia.

Iniciaremos nossa análise explorando as entrevistas dos jovens pertencentes ao primeiro grupo (nova economia internet, telecomunicações e informática - e setor bancário pós-reestruturação).

\section{Setor bancário pós-reestruturação}

O número de trabalhadores do setor bancário diminuiu em 50\% na década de 90 no Brasil (DIEESE, 2002), devido a um processo radical de reestruturação organizacional associada a uma ampla informatização dos serviços. O banco no qual trabalham os entrevistados pertence a um poderoso grupo espanhol. A instituição trocou cinco vezes de nome e de controle de capital nos anos 90, seguindo o fluxo intenso de fusões e aquisições que marca o período do turbo-capitalismo. A maior parte dos empregados mais velhos foi demitida no processo de reestruturação.

As tarefas bancárias também se transformaram completamente. A maior parte das funções burocráticas foi informatizada e os empregados se tornaram vendedores de produtos. O banco fixa cotas de venda (metas de produtividade) extremamente elevadas para cada agência (imposição coletiva) e para cada “colaborador” (imposição individual). Uma boa parte do salário depende do sucesso em atingir as cotas, mesmo que parcialmente, uma vez que o salário fixo é pouco atrativo. As ferramentas de gestão ligadas às competências “interpessoais” são largamente utilizadas como es- tratégia de motivação para o incremento das vendas e como forma de interiorização do discurso de valorização da competição interna à empresa (entre colegas) e externa (entre os bancos). As competências técnicas são percebidas pelos jovens como tendo importância secundária em relação às competências interpessoais para o ingresso no mercado de trabalho e para o sucesso profissional.

Uma longa carreira em uma mesma empresa não é algo almejado, mesmo acreditando que o banco oferece verdadeiras possibilidades de carreira para aqueles que são "agressivos” na busca do sucesso e que interiorizaram o espírito da empresa. A partir desta lógica, a troca de empregos e a acumulação de experiências são percebidas como um valor agregado à pessoa no mercado de trabalho.

Os entrevistados foram contratados como estagiários logo no início do curso de administração de empresas. A seleção foi rigorosa e privilegiou os candidatos mais agressivos e competitivos. Eles foram rapidamente promovidos ao cargo de gerente de conta após uma formação intensiva baseada, sobretudo, em técnicas de motivação. O marketing interno do banco é muito eficaz e eles dizem-se orgulhosos de pertencer ao décimo maior banco do mundo. Eles também se dizem felizes no trabalho, mas ao mesmo tempo afirmam ter de ser felizes para trabalhar. A felicidade faz parte das qualidades necessárias para ingressar e se manter no mercado.

A competição interna entre os trabalhadores, as taxas elevadas de desemprego no setor e as constantes trocas de controle de capital do banco criaram um clima de insegurança e de instabilidade. Entretanto, este clima é considerado como normal. A lógica central da forma de implicação no trabalho e na sociedade é aquela do poder supremo do indivíduo. As relações sociais produzidas a partir da competição como valor central e da sobrevivência do mais forte/apto/competente são naturalizadas. O indivíduo é considerado todo poderoso e capaz de ultrapassar qualquer dificuldade. O mundo é feito para aqueles que aproveitam as oportunidades e que se adaptam às transformações impostas pelo mercado. A lógica da seleção natural é utilizada como metáfora do mercado de trabalho. A forma de se posicionar em relação ao trabalho e à sociedade evidencia-se na reflexão utilizada para responder ao dilema ético. A reflexão constrói-se a partir de uma lógica individualista e instrumental. A decisão de testemunhar ou não em defesa do colega é ligada a um julgamento de custobenefício. Todos os entrevistados acreditam que os colegas não testemunhariam. No caso de se colocar na situação, aque-

Tabela 1

Distribuição dos entrevistados face à inserção profissional e o setor econômico

\begin{tabular}{clcc}
\hline Inserção profissional & \multicolumn{1}{c}{ Setor } & Participantes & Total \\
\hline Mercado formal & Banco pós-reestruturação & 5 & \\
& $\begin{array}{l}\text { Nova economia (telefonia } \\
\text { celular/Internet/informática) }\end{array}$ & 15 & 20 \\
Mercado informal & Economia solidária: galpão de reciclagem & 5 & 10 \\
\hline Total & Projeto comunitário: telecentro & 5 & 30 \\
\hline
\end{tabular}


les poucos que testemunhariam, o fariam porque crêem que a decisão os ajudará a galgar alguns degraus na carreira dentro da empresa porque a ética está na moda. Nas respostas dos jovens, percebe-se um cinismo que se integra como regra de conduta em relação aos colegas de trabalho e como norma de sobrevivência nas estratégias de inserção na sociedade.

A maior parte dos jovens não é sindicalizada. O sindicato, na opinião deles, não tem um papel importante na defesa dos direitos conquistados, pois não tem força no enfrentamento direto com as empresas e porque deturpou seu objetivo tornando-se excessivamente político. Esta idéia, que está fortemente ancorada no imaginário, contrasta com a história do sindicato do setor que foi um dos mais fortes na história brasileira recente.

Os jovens não se interessam pela política. Os entrevistados mais convencidos da verdade contida nas prescrições do discurso de gestão são os mais individualistas nas formas de inserção no trabalho e na sociedade. Os sentimentos e as lógicas evidenciados pela análise das entrevistas denotam certa ambigüidade quando a temática da entrevista girava em torno dos problemas sociais como a miséria, a violência, a pobreza, ou mesmo, a possibilidade de pensar o futuro no longo prazo. Entretanto, invariavelmente, após um momento de hesitação, a lógica do indivíduo todo-poderoso impunha-se como uma defesa psíquica contra as mazelas do contexto social.

\section{Nova economia - telefonia móvel, Internet e informática}

Existem algumas diferenças importantes no mercado de trabalho das profissões ligadas à Internet, à informática e à telefonia. Estas diferenças referem-se às características e à história de cada setor. O mercado da telefonia móvel é mais tradicional, uma vez que, num primeiro momento, ele estruturou-se a partir das empresas de telefonia fixa através da privatização das estatais, abrindo-se, somente num segundo momento, ao mercado internacional. A base do capital das empresas do setor é, hoje, multinacional. O mercado estava em expansão até o fim de 2001. Após, a previsão de crescimento foi revista e hoje o mercado é mais competitivo. Muitas das empresas já iniciaram os processos de reestruturação com fusão dos grupos iniciais, processo esse acompanhado dos habituais enxugamentos de pessoal.

As estatísticas públicas para o setor da informática e Internet não se adaptaram às ocupações da nova economia e ainda é difícil compreender o cenário do mercado de trabalho. As análises parciais existentes indicam que ainda existe demanda de profissionais no setor, sobretudo daqueles com alta qualificação técnica. O setor hoje se compõe de uma diversidade muito grande de formas de inserção profissional, que vão da pequena empresa local às grandes empresas multinacionais, passando pelos profissionais autônomos que prestam serviço na forma de assessoria como profissionais liberais, pelo setor público e até por formas de inserção precárias no mercado informal. O setor ainda não é dominado pelas grandes empresas multinacionais como é o caso da telefonia móvel. Ainda como uma marca diferencial importan- te, podemos dizer que os profissionais da informática encontram uma grande possibilidade de mobilidade em múltiplas áreas da economia, devido à onipresença da informática.

O profissional típico do setor é um jovem com diploma universitário na área de informática, engenharia ou em administração de empresas. A adesão aos novos discursos de gestão é mais freqüente nos profissionais ligados à área de administração/marketing do que naqueles que se ocupam mais exclusivamente da área técnica. Os profissionais técnicos mantêm certa distância moral da lógica competitiva das empresas. As trocas de conhecimento tecnológico, as quais fazem parte da necessidade permanente de atualização, os impelem a valorizar o trabalho em equipe. São jovens que se identificam com a lógica do empreendedorismo e acreditam poder construir uma carreira baseada nas competências pessoais. Entretanto, não estão seguros para realizar um planejamento do futuro no longo prazo. A velocidade das mudanças no setor impede uma visão clara do futuro. Eles estão habituados às mudanças e naturalizaram os riscos associados à carreira. O desenvolvimento da competência técnica e a atualização permanente são as armas utilizadas para enfrentar as incertezas do futuro.

No setor da telefonia, uma característica marcante é a identificação com o marketing externo das empresas. A identificação com a imagem publicitária altamente utilizada pela companhia é motivo de orgulho e, dentro desta mesma lógica, os profissionais reconhecem que a relação com esta é dotada do mesmo caráter efêmero da publicidade. Eles jogam o jogo da empresa e dizem que se deve ficar no mesmo emprego somente o tempo necessário para “agregar valor” à carreira. A referência às competências emocionais (ou interpessoais) é uma constante nas características descritas como necessárias para ingressar no mercado de trabalho. Além das competências emocionais e técnicas, o domínio de uma ou duas línguas estrangeiras é considerado essencial. O inglês, sobretudo com relação à área técnica, e o espanhol em razão da língua matriz da companhia (a qual detém a maior fatia do mercado no Rio Grande do Sul), além do interesse comercial no Mercosul.

A resolução do dilema ético acompanha as diferenças já descritas entre os profissionais técnicos e aqueles ligados ao marketing e à administração.

Os analistas de sistema crêem no valor da verdade e da honestidade nas relações de trabalho. Eles se dizem prontos a deixar uma empresa na qual não exista uma relação de confiança entre colegas. Esta resposta se associa às possibilidades de mobilidade dentro de um mercado que ainda necessita de profissionais qualificados. Além deste fato, a confiança é a base de um trabalho em rede que depende da cooperação entre os membros da equipe.

Os profissionais ligados aos setores de administração e marketing, por sua vez, são os mais contaminados pela razão cínica já descrita na análise dos jovens do setor bancário.

Outro fator importante que as entrevistas denotam é a ruptura com os valores morais associados ao trabalho, característicos da geração dos pais destes jovens. Nada do que eles aprenderam com relação ao trabalho é válido para o coti- 
diano. O mundo mudou completamente e os jovens trabalham em uma área não imaginada pelos pais. É um mundo novo entendido como pleno de possibilidades, mas, ao mesmo tempo, muito incerto e muito injusto. A solução encontrada para a busca da felicidade não é diferente daquela encontrada nos outros grupos de jovens, ou seja, a busca individual do sucesso.

\section{Economia solidária e associativismo comunitário}

O grupo é composto por 10 jovens de até 30 anos, divididos em dois subgrupos. O primeiro é composto por trabalhadores de um galpão de reciclagem localizado em um bairro da região periférica de Porto Alegre. O segundo subgrupo é formado por voluntários que se engajaram em um projeto da Prefeitura Municipal, denominado Telecentro, e desenvolvem um projeto de monitoria em computação para moradores da comunidade. Os subgrupos diferem no nível de escolaridade: os recicladores não concluíram o ensino fundamental, enquanto os monitores de informática têm o nível médio completo, além de curso técnico em processamento de dados.

Ambos os projetos, embora desenvolvidos por membros da comunidade local, são financiados parcialmente por verbas municipais. O galpão de reciclagem foi criado a partir da mobilização da população dentro do Orçamento Participativo da cidade. A prefeitura de Porto Alegre, via Secretaria Municipal da Indústria e Comércio, disponibilizou o prédio do empreendimento assim como as prensas utilizadas para a compactação do lixo.

O projeto do Telecentro também conta com uma parceria com a Companhia de Processamento de Dados do Município de Porto Alegre (PROCEMPA), que disponibiliza os computadores, sua manutenção e suporte aos monitores, além de bolsas para dois menores aprendizes e um monitor adulto. Os outros monitores envolvidos trabalham voluntariamente. A comunidade contribui com um local para o desenvolvimento do projeto e com a arrecadação dos encargos para o pagamento de água, luz, limpeza e segurança do mesmo. Os voluntários encontram-se desempregados ou prestam serviços no mercado informal.

Os entrevistados demonstram orgulho das organizações em que trabalham, justificando a importância das mesmas, no primeiro subgrupo devido à função ecológica da reciclagem do lixo e, no segundo, pela difusão do conhecimento na informática. Entretanto, o ingresso dos jovens nos empreendimentos não se dá primordialmente pela identificação com a questão ideológica, mas pela falta de alternativa econômica e na perspectiva de que estes vínculos sejam uma passagem transitória até conseguirem um emprego no mercado formal.

Tal desvinculação com o projeto de economia solidária pode ser observada na alienação em relação ao funcionamento do galpão e ao processo de produção como um todo. A execução do trabalho é feita de forma muito semelhante aos moldes de uma empresa de organização do trabalho taylorista, excetuando-se a divisão dos lucros (embora aqui eles também não acompanhem os preços de mercado e as negociações para venda do material separado para reciclagem).
Da mesma forma, os jovens do Telecentro não vêem o mesmo como uma oportunidade de inclusão digital da população, mas como uma forma de afastamento dos jovens da comunidade do envolvimento com as drogas ou com a violência. O lugar desse projeto em suas vidas está bastante ligado à busca de novas oportunidades de emprego na área de informática.

Os entrevistados dos dois subgrupos almejam conseguir empregos em postos de trabalho tradicionais com carteira assinada e com as garantias a ela associadas. Eles acreditam na possibilidade de permanecer por um longo tempo em uma empresa, sendo poucos os que prefeririam desenvolver um negócio próprio. Contudo, os jovens descrevem o perfil de um trabalhador com poucas chances no mercado de forma muito semelhante às suas próprias características, como eles mesmos dizem: baixa escolaridade, má aparência e cor negra.

A importância do trabalho é justificada como forma de garantir o sustento, como valor moral e recurso para "distrairse” dos problemas pessoais/sociais. Os jovens reconhecem a escassez de vagas no mercado atual. No entanto, consideram a escolaridade mais alta como condição suficiente para encontrar um bom emprego. A felicidade almejada é representada pelos vínculos de proximidade e o desejo de sair da situação de vulnerabilidade permanente, podendo desta forma estar cercado de pessoas amigas, ter segurança e saúde pessoal e familiar. Os desejos futuros envolvem melhorar o padrão de vida, conseguir um trabalho mais qualificado e adquirir bens próprios, como casa e, em alguns casos, carro. A impossibilidade de planejar o futuro ancora-se nas decepções acumuladas na não concretização de planos anteriores. Os trabalhadores almejam que suas esperanças não alcançadas sejam realizadas pelos filhos.

A competição e o individualismo são valores presentes no discurso sobre as possibilidades de ingresso no mercado de trabalho. Da mesma forma, fazer a opção pela omissão (não testemunhar) na resolução do dilema ético é vista como a única alternativa viável. Embora seja considerada como uma opção incorreta em termos morais, esta é justificada pela necessidade de sobrevivência. Tal resposta é mais característica daqueles jovens cuja trajetória de vida é marcada por um maior grau de vulnerabilidade social, a qual pode ser associada à falta de suportes sociais e familiares, como é o caso dos trabalhadores do galpão de reciclagem e dos jovens desempregados que são voluntários no Telecentro.

\section{Conclusão: excesso e falta, as transformações do capitalismo e o laço social}

O exercício de comparação entre os relatos dos trabalhadores da economia solidária e dos jovens da nova economia evidencia de forma clara o fosso social brasileiro. As diferenças de recursos e competências pessoais adquiridos ao longo da vida, associadas à ausência e/ou fragilidade dos suportes sociais, nos possibilita construir um esquema explicativo das desigualdades que marcam as possibilidades de inserção no mercado de trabalho. 
Encontramos nos relatos regularidades ligadas aos dispositivos associados ao novo discurso de gestão, os quais agenciam os processos de subjetivação dos jovens dos setores bancário e da nova economia. Esse discurso constrói o eu ideal em torno de um indivíduo onipotente e capaz de enfrentar de forma solitária a reestruturação organizacional e tecnológica associada às transformações do capitalismo. A construção desse eu ideal produz efeitos nas formas de reflexão ética utilizadas pelos jovens nas decisões que marcam sua inserção no laço social.

A adesão completa ao discurso hegemônico de gestão acompanha-se de uma adesão à lógica do darwinismo social e do liberalismo selvagem. A ilusão individualista, o reino do privado e da competição transformaram-se em modos de regulação da vida.

Esses jovens se enquadram no perfil descrito pelo novo discurso gerencial e também pela literatura psicossociológica como trabalhadores flexíveis, móveis, empreendedores (Boltanski \& Chiapello, 1999) e adaptados às exigências do mercado de trabalho pós-terceira revolução industrial e globalizado. Estes trabalhadores atravessaram processos de subjetivação inundados pelo regime de verdade referente ao trabalho que configura um contexto espaço-temporal distinto daquele da modernidade. Encontramos nas entrevistas uma tensão permanente que, por um lado, evidencia uma pretensa maior autonomia, liberdade e possibilidades de escolha com relação aos projetos de vida e, pelo outro, uma transformação radical em relação à segurança ontológica e à vivência de uma temporalidade que permitiu à geração dos pais, o planejamento da vida e a construção do caráter - no sentido que Sennet (1998) atribui a este termo. Nesta direção, Gauchet (1998) afirma que estaríamos entrando em uma nova fase, na qual assistimos ao surgimento de uma "personalidade” contemporânea desconectada simbólica e cognitivamente do todo social. Um indivíduo para o qual o conjunto da sociedade não faz sentido. Pela primeira vez na história teria sido possível produzir um indivíduo que ignora que vive em sociedade, que não comporta um senso de responsabilidade para com as regras sociais. Este hiperindividualismo conduziria a um sentimento de não ser nada e não estar em lugar nenhum. A partir de uma perspectiva semelhante, Enriquez (1997) afirma que a questão ética tornou-se central na nossa sociedade, pois o mal-estar de nossa época é reforçado pelo aumento do individualismo. Este se apresenta sob uma forma narcisista, que é conseqüência da impossibilidade de pensar o futuro e, por esta razão, produz uma incontrolável vontade de aproveitar os momentos da forma mais intensa e imediata possível.

Esta perspectiva de um presente ansioso e angustiado demarca a ausência de princípios que forneçam sentido para a vida em comum, apontando assim para a fragilidade do laço social e, ao mesmo tempo, para o excesso de individualismo causado pela destruição dos valores da modernidade e pela dissociação dos laços centrados no trabalho. Sem, entretanto, que esses valores tenham sido substituídos por qualquer outro que não seja o consumo da própria existência. Ortega (1999) afirma que é somente o encontro e o respeito pelo outro na sua alteridade absoluta e o reconhecimento da finitude do ser e dos limites de cada ser que permitem destruir com a tirania do eu e possibilitam a solidariedade.

Na visão de todos os jovens entrevistados, o mundo se transformou profundamente e ele é mais injusto, mais violento, mais desigual. Entretanto, esta constatação não é acompanhada por qualquer sentimento de responsabilidade para com a transformação do contexto social. Aqueles que aderem de forma totalitária ao discurso da aventura empreendedora e do indivíduo conquistador (Ehrenberg, 1996) são aqueles que demandam ao Estado medidas duras de repressão à criminalidade sem se perguntar das causas do incremento da violência. Aqueles que são mais críticos com relação ao discurso do desempenho individual/competição como valor central, ou que, pelo menos, crêem na construção de regras e de limites para os jogos do mercado, defendem a necessidade do investimento em políticas públicas em saúde e educação.

De acordo com Castel (1998), a nova ordem ameaça uma série de conquistas que qualificaram o locus societário dos trabalhadores e possibilitaram associar ao trabalho o acesso à proteção social, representada pela seguridade social e pelas políticas públicas que afastaram os trabalhadores do imperativo da necessidade. Castel demonstra a construção da categoria dos supranumerários e dos desfiliados como produto da fratura (ou prenúncio desta) que assombra as sociedades contemporâneas e empurra para o primeiro plano as temáticas da precariedade, do desterro e da desfiliação. Aponta também para homologias de posição entre os inúteis para o mundo, representados pelos vagabundos do período anterior à revolução industrial, e as diferentes categorias de inempregáveis de hoje.

Nos relatos dos jovens que participam de projetos ligados à economia solidária, encontramos a lógica da sobrevivência como ordenadora do discurso. A seleção "natural” se apresenta na defesa da competição como única maneira para conseguir se manter vivo. Embora esse subgrupo tenha um discernimento acerca do contexto de vulnerabilidade em que vive e não se identifique com o liberalismo como solução para seus problemas, o mesmo afirma que não é possível ter uma renda satisfatória para sustentar suas necessidades dentro dos movimentos em que se insere. Assim, mesmo tendo uma visão crítica acerca da importância do papel regulador do governo no mercado e pela via da seguridade social, os jovens não conseguem efetivar um projeto que busque transformar a configuração social. Sua vinculação aos empreendimentos solidários é vista como temporária e o emprego é considerado um quebra-galho para diminuir sua condição precária, mas que será substituído prontamente caso surja uma oportunidade de emprego melhor remunerado e estável. A ambição dos jovens centrase no sonho de conseguir uma posição no mercado formal que lhes permita ter segurança.

Nossa análise indica que os projetos de economia solidária estudados não se apresentam como real opção aos trabalhadores no mercado de trabalho. Esses funcionam apenas como alternativa ao desemprego, não se constituindo efeti- 
vamente como um contraponto à posição central ocupada pelas atuais formas de gestão.

As transformações contemporâneas do capitalismo têm conseqüências para a estrutura e dinâmica da coesão social em todo o mundo. As novas guerras, a violência urbana crescente e o terrorismo são bons exemplos dos efeitos da nova configuração da sociedade sob a égide do mercado. Entretanto, nas sociedades mais desiguais e com economias mais frágeis, como é o caso do Brasil, as conseqüências são mais duras, uma vez que a tarefa de diminuição das desigualdades e a construção de uma sociedade mais igualitária depende de transformações nas formas de implicação no laço social. Se, como constatamos nas entrevistas com os jovens, as formas de adesão ao discurso de gestão acompanha as formas de implicação no laço social, estamos caminhando na direção contrária de um pacto social que visa à construção de uma sociedade mais justa.

O exemplo que segue, mesmo se tratando de um relato particularmente forte, ilustra bem nosso argumento. Entrevistamos um jovem diretor de uma empresa de informática, que nos disse: "Eu não gosto de ser brasileiro, acho que nasci no lugar errado. Eu não consigo ter patriotismo pelo Brasil porque eu não vejo ele me ajudando em nada, estou comprando o meu passaporte para a minoria.”

\section{Referências}

Beaud, S., \& Weber, F. (1998). Guide de l'enquête de terrain. Paris: La Decouverte. Boltanski, L., \& Chiapello, E. (1999). Le nouvel esprit du capitalisme. Paris: Gallimard.

Bourdieu, P. (1986) L'illusion biographique. Actes de la Recherche en Sciences Sociales, 62/63, 69-72.

Buffet, J. (1991) 1500-2000 Étude d'un processus de dévéloppement sous l'hypothèse d'industrialisation tardive et analyse des métamorphoses de sa violence politique, économique et sociale. Tese de doutorado não-publicada, Universidade de Grenoble 2, Grenoble.
Cabanes, R. (2002). Travail, famille, mondialisation. Paris: IRD/KARTHANA.

Castel, R. (1998). As metamorfoses da questão social: uma crônica do salário. Petrópolis: Vozes.

Castel, R., \& Haroche, C. (2001). Propriété privée, propriété sociale, propriété de soi: entretiens sur la construction de l'individu moderne. Paris: Fayard.

Colbari, A. L. (1995). Ética do trabalho: a vida familiar na construção da identidade profissional. São Paulo: UFES - Letras e Letras.

Deleuze, G. (1986). Foucault. Paris: Minuit.

Departamento Intersindical de Estatística e Estudos Sócio-Econômicos (2002). A situação do trabalho no Brasil. São Paulo: Autor.

Ehrenberg, A. (1996). Le culte de la performance. Paris: Hachete-Pluriel.

Enriquez, E. (1997). Les jeux du pouvoir et du désir dans l'entreprise. Paris: Descleé de Brouwer.

Ferraroti, F. (1983). Histoire et histoires de vie: la méthode biographique dans le sciences sociales. Paris: Librairie des Meridiens.

Ferraroti, F., \& Crespi, F. (1994). La parola operaria: cento anni di storia di vita operaria (1892-1992). Turim: Aquila.

Fonseca, M. A. (1995). Michel Foucault e a constituição do sujeito. São Paulo: EDUC.

Foucault, M. (1987). A arqueologia do saber. Rio de Janeiro: Forense Universitária.

Foucault, M. (1994). L'éthique du souci de soi comme pratique de la liberté. In Dits et Ecrits (pp. 708-729). Paris: Gallimard.

Gauchet, M. (1998). Essai de psychologie contemporaine. Un nouvel âge de la personnalité. Le Débat, 99, 164-181.

Giddens, A. (1989). A constituição da sociedade. São Paulo: Martins Fontes.

Gomes, A. M. C. (1982). O redescobrimento do Brasil. In L. Oliveira, M. P. Velloso, \& A. M. C. Gomes (Orgs.), Estado Novo: ideologia e poder (pp. 25-36). Rio de Janeiro: Zahar.

Nardi, H. C., Tittoni, J., \& Bernardes, J. (2002). Subjetividade e trabalho. In A. D. Cattani (Org.), Dicionário crítico sobre trabalho e tecnologia (pp. 302309). Petrópolis: Vozes.

Ortega, F. (1999). Amizade e estética da existência em Foucault. Rio de Janeiro: Graal.

Petras, J. (1999). Neoliberalismo: América Latina, Estados Unidos e Europa. Blumenau: FURB.

Santos, W. G. (1979). Cidadania e justiça: a política social na ordem brasilei$r a$. Rio de Janeiro: Campus.

Sennett, R. (1998) The corrosion of character: personal consequences of work in the new capitalism. Nova York: Norton.

${ }^{1}$ Mesmo que no Brasil não tenhamos tido um processo completo de industrialização, como podemos ver pelos dados históricos de distribuição da produção por setor econômico, o trabalho na indústria teve papel central no imaginário social brasileiro, inicialmente com Vargas, posteriormente com Juscelino e afirmando-se definitivamente no período da ditadura militar (Buffet, 1991).

${ }^{2}$ No Apêndice encontra-se o dilema ético utilizado para investigar as implicações dos participantes nas relações com seu contexto por meio da forma como estes realizam o julgamento moral de suas ações.

Henrique Caetano Nardi, doutor em Sociologia pela Universidade Federal do Rio Grande do Sul, é professor no Programa de Pós-graduação em Psicologia Social e Institucional da Universidade Federal do Rio Grande do Sul. Endereço para correspondência: Rua Miguel Tostes, 814 apto. 304; Porto Alegre, RS; CEP 90430-060. Tel/Fax: (51) 3330-8628.E-mail: hcnardi@aol.com

Denise Balem Yates, psicóloga e bolsista do Programa Institucional de Iniciação Científica - PROBIC da Universidade Federal do Rio Grande do Sul / Fundação de Amparo á Pesquisa do Estado do Rio Grande do Sul. 


\section{Apêndice}

Dilema Ético (apresentado durante a entrevista)

\section{Para os jovens da nova economia e setor bancário pós-reestruturação}

Um gerente local será promovido, pois o gerente regional será demitido devido a uma acusação de envolvimento em fraude. O gerente local que será promovido sabe que a acusação é falsa e tem provas para defender o gerente regional, entretanto, ninguém sabe que ele sabe e, caso exponha o que sabe, perderá a chance da promoção. O que você acha que a maioria de seus colegas faria nesta situação?

Na sua opinião, quais os fatores que pesam na decisão?

Esta ação é correta?

O que você faria neste caso e por quê?

\section{Para os jovens da economia solidária/projeto comunitário}

O vice-presidente de uma associação será promovido, pois o presidente será demitido devido a uma acusação de envolvimento em fraude. O vice-presidente que será promovido sabe que a acusação é falsa e tem provas para defender o presidente, entretanto, ninguém sabe que ele sabe e, caso exponha o que sabe, perderá a chance da promoção. O que você acha que a maioria de seus colegas faria nesta situação?

Na sua opinião, quais os fatores que pesam na decisão?

Esta ação é correta?

$\mathrm{O}$ que você faria neste caso e por quê? 